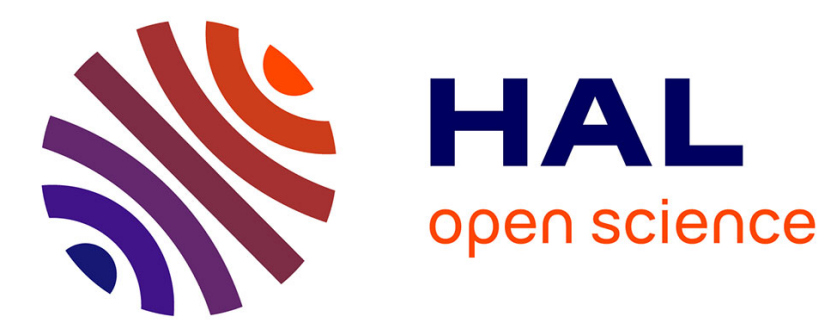

\title{
Analysis of a thermoviscoelastic model in large strain
}

Stéphane Méo, Adnane Boukamel, Olivier Débordes

\section{To cite this version:}

Stéphane Méo, Adnane Boukamel, Olivier Débordes. Analysis of a thermoviscoelastic model in large strain. Computers \& Structures, 2002, 80, pp.2085-2098. 10.1016/S0045-7949(02)00246-8 . hal01236414

HAL Id: hal-01236414

https://hal-univ-tours.archives-ouvertes.fr/hal-01236414

Submitted on 10 Feb 2018

HAL is a multi-disciplinary open access archive for the deposit and dissemination of scientific research documents, whether they are published or not. The documents may come from teaching and research institutions in France or abroad, or from public or private research centers.
L'archive ouverte pluridisciplinaire HAL, est destinée au dépôt et à la diffusion de documents scientifiques de niveau recherche, publiés ou non, émanant des établissements d'enseignement et de recherche français ou étrangers, des laboratoires publics ou privés. 


\title{
Analysis of a thermoviscoelastic model in large strain
}

\author{
S. Méo ${ }^{\mathrm{a}, *}$, A. Boukamel ${ }^{\mathrm{a}, \mathrm{b}}$, O. Débordes ${ }^{\mathrm{a}}$ \\ ${ }^{a}$ Laboratoire de Mécanique et d'Acoustique de Marseille, UPR CNRS 7051, IMT/ESM2, Technopole de Château Gombert, \\ 13451 Marseille Cedex 20, France \\ ${ }^{\mathrm{b}}$ Ecole Supérieure d'Ingénieurs de Marseille, Technopole de Château Gombert, 13451 Marseille Cedex 20, France
}

\section{Introduction}

Nowadays, elastomers are frequently employed in many sectors such as automobile and aeronautics industries. In their uses, these materials can undergo strong mechanical and thermal loadings. Moreover their mechanical properties highly depend on the temperature and thus the prediction of the behaviour and the assessment of the fatigue strength require a local analysis based on a formulation of thermomechanical models.

The behavior of an elastomer can be very different according to:

- the temperature,

- the degree of crosslinking,

- the incorporated particles (carbon black or silicium filled rubbers)

- ...

So we can distinguish several approaches in the literature in accordance with the considered phenomenon:

\footnotetext{
${ }^{*}$ Corresponding author. Fax: +33-4-91-05-44-58.

E-mail address: meo@imtumn.esm2.imt-mrs.fr (S. Meo).
}

- hyperelasticity modeling the static behaviour of the material,

- continuum damage mechanics approaching the softening behaviour under deformation, currently call Mullins' effect [28],

- nonlinear viscoelasticity for the simulation of the relaxation phenomenon and the eventual dissipation,

- thermomechanical coupling to take temperature sensitivity of mechanical characteristics into account and to describe the temperature changes due to the mechanical dissipation.

More precisely, for hyperelasticity several stress strain relationships are proposed which are based on the expression of strain energy density in the isotropic, incompressible materials or very nearly so (almost incompressible). Among these behaviour laws, statistical models were carried out with entropic consideration of the molecular chains configurations [38,39], an other way consists in a phenomenological approach deduced from isotropy and incompressibility. These last ones must be adjusted according to experiment $[12,26,31$, 32].

Rubber materials, especially carbon black-filled, present a softening effect experimentally observed [13]. This loss of stiffness can be micro-mechanically described by a local separation of the carbon and rubber. 
- Coupling the aspects of statistical mechanics and composite material theory, Govindjee and Simo [10] propose a first model. It is based on the relation between the free energy for a statically representative sample volume and the polymer chains free energy (the particles are assumed to be rigid). This last energy is additively split into the contribution of the chains that are crosslinked on both ends and the contribution of the chains attached on both ends to carbon particles.

Some phenomenological considerations allow an efficient numerical implementation of this model [9].

- A complete phenomenological model is describe by Simo [37] for a viscoelastic material. It includes softening behavior under deformation for a cyclic test with increasing amplitude.

The last two models take only discontinuous damage into account because the damage is related to the maximum stretch of the deformation history for the first and to the maximum effective strain energy for the second. But, experimental investigations show that the filled polymers present a damage accumulation for all strain cycles and not only for increasing amplitude strain cycles. To take this into account, Miehe [25] uses a damage evolution governed by the arclength of the effective strain-energy.

Furthermore, concerning the nonlinear viscoelastic aspects the formulations are categorized as follows:

- the integral approach principally developed for nonlinear materials with fading memory and which give the stress tensor according to the strain history [4, $5,32]$.

The finite linear viscoelasticity method $[6,21]$ is a direct application. It is based on a modified linear Boltzmann superposition principle with a nonlinear strain measure. It uses an asymptotic expansion of relaxation functions. The separability principle between strain and time is expressed by the first term of the expansion, while the higher order terms constitute a correction. More recently, a generalized deformation measure is proposed in a modified finite linear viscoelasticity theory $[3,27]$.

- the differential approach is based on the concept of intermediate state commonly used to describe finite elastic-plastic deformations [33,34]. It can be saw as a generalization to large strains of classical rheological models $[17,18,20,36]$. The local state method [19] constitutes the theoretical frame of this formulation, the internal variables being introduced by the intermediate states.
These approaches are often more adapted to nuerical developments.

The inelastic material properties of elastomers involve an internal heat production and thus an increase of the temperature. This thermomechanical coupling phenomenon is studied by Holzapfel and Simo [15], but this paper is only concerned with the linear viscoelasticity. The theoretical framework of a fully coupled thermomechanical behaviour for finite strains is developed in the case of elasticity in [15] by the decomposition of transformation into a thermal one and an elastic one. The same idea is employed by Lion [22] but instead of an elastic part, the mechanical transformation is viscoelastic. The internal variables of this models correspond to inelastic deformations tensors. Holzapfel and Simo [16] realized the same description but using internal variables of stress type. All these studies give guidelines to handle nonisothermal problems, taking thermomechanical coupling into account.

Besides the mechanical (or thermomechanical) behaviour, on the numerical aspects, many works contribute to the development of mathematical formulation and numerical methods allowing precise simulations of hyperelastic or viscoelastic materials. These finite element formulations allow the large strains and take the incompressibility constraint into account using a penalty method [23,29] or an augmented Lagrangian method [8] in order to solve the equilibrium problem in hyperelasticity. Le Tallec and Rahier [18] use a similar approach for the nonlinear viscoelasticity with a local treatment of internal variables.

In this paper, we present a thermoviscoelastic model for large deformation and finite variations of temperature. It is based on a fully phenomenological approach, on irreversible thermodynamics and on the local state method.

After a presentation of the mechanical, thermal and coupling aspects, we will give an influence analysis of different parameters taking into account in these aspects.

\section{Model presentation}

\subsection{Kinematical description}

Consider a body occupying the domain $\Omega$ in the undeformed $C_{0}$ and $\omega$ in the current configuration $C_{t}$ (Fig. 1).

As usual, $\overline{\bar{C}}$ defines the right Cauchy-Green tensor, $\overline{\bar{E}}$ the Euler-Almansi strain tensor, $\overline{\bar{L}}$ the velocity gradient and $\overline{\bar{D}}$ the rate of deformation. They can be defined from $\overline{\bar{F}}$ the deformation gradient:

$\overline{\bar{C}}=\overline{\bar{F}}^{\mathrm{T}} \cdot \overline{\bar{F}}$, 


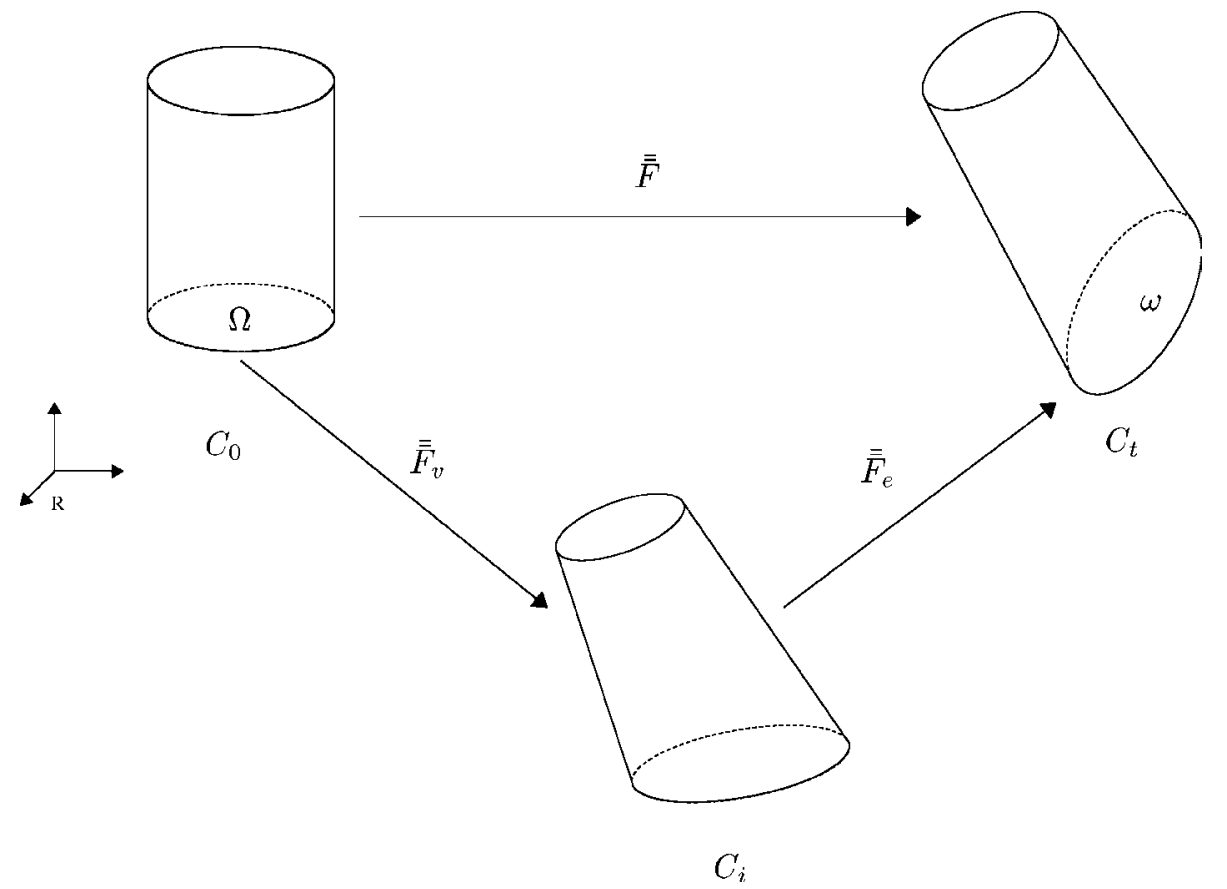

Fig. 1. System configurations.

$\overline{\bar{E}}=\frac{1}{2}(\overline{\bar{C}}-\overline{\overline{1}})$,

$\overline{\bar{L}}=\dot{\bar{F}} \cdot \overline{\bar{F}}^{-1}$,

$\overline{\bar{D}}=\frac{1}{2}\left(\overline{\bar{L}}+\overline{\bar{L}}^{\mathrm{T}}\right)$.

The additive decomposition of infinitesimal strain tensor $(\overline{\bar{\varepsilon}})$ into an elastic part $\left(\overline{\bar{\varepsilon}}_{\mathrm{e}}\right)$ and an inelastic one $\left(\overline{\bar{\varepsilon}}_{\mathrm{a}}\right)$ :

$\overline{\bar{\varepsilon}}=\overline{\bar{\varepsilon}}_{\mathrm{e}}+\overline{\bar{\varepsilon}}_{\mathrm{a}}$

can be extended to large deformation by means of the intermediate state $C_{\mathrm{i}}$ (Fig. 1) [35]. Introducing $\overline{\bar{F}}_{\mathrm{e}}$ and $\overline{\bar{F}}_{\mathrm{v}}$ respectively, the pseudo-gradients of elastic and viscous motion, the deformation gradient can be decomposed as:

$\overline{\bar{F}}=\overline{\bar{F}}_{\mathrm{e}} \cdot \overline{\bar{F}}_{\mathrm{v}}$.

It is possible to define an elastic and a viscous dilatation tensor:

$\overline{\bar{C}}_{\mathrm{v}}=\overline{\bar{F}}_{\mathrm{v}}^{\mathrm{T}} \cdot \overline{\bar{F}}_{\mathrm{v}}$,

$\overline{\bar{C}}_{\mathrm{e}}=\overline{\bar{F}}_{\mathrm{e}}^{\mathrm{T}} \cdot \overline{\bar{F}}_{\mathrm{e}}$.

\subsection{Thermodynamic formulation}

The system transformation is governed by three conservation laws of the classical thermodynamics, locally written in Lagrangian description.

- Mass conservation:

$\rho(\operatorname{det} \overline{\bar{F}})=\rho_{0}$,

- Momentum conservation:

$\rho_{0} \ddot{\vec{u}}=\operatorname{div}_{X} \overline{\bar{\pi}}+\rho_{0} \vec{f}$,

- Energy conservation:

$\rho_{0} \dot{e}=\overline{\bar{\pi}}: \dot{\bar{F}}-\operatorname{div}_{X} \vec{Q}+\rho_{0} r$

with $\rho_{0}$ and $\rho$ respectively the local density mass in $C_{0}$ and $C_{t}, \overline{\bar{\pi}}$ the first Piola-Kirschhoff stress tensor, $\vec{f}$ the specific forces, $e$ the specific internal energy, $\vec{Q}$ the PiolaKirschhoff heat flux and $r$ the rate of heat production per unit mass. According to the theory of the thermodynamics of irreversible processes (local state method [19]), an independent set of thermodynamics variables is chosen (see [7]): $\left(\overline{\bar{C}}, \overline{\bar{C}}_{\mathrm{v}}, T\right)$, where $T$ is the absolute temperature.

Introducing $\psi$, the specific free energy, as a function of this variables set and (11) in the Lagrangian description of the Clausius-Duhem inequality: 


$$
\phi_{0}=\underbrace{\left(\pi-\frac{\partial \psi}{\partial \overline{\bar{F}}}\right): \dot{\bar{F}}-\rho_{0}\left(\eta+\frac{\partial \psi}{\partial T}\right) \dot{T}-\rho_{0} \frac{\partial \psi}{\partial \overline{\overline{C_{\mathrm{v}}}}}: \dot{\overline{\bar{C}}}_{\mathrm{v}}}_{\phi^{\text {int }}} \underbrace{-\frac{1}{T} \vec{Q} \cdot \operatorname{grad}_{X} T}_{\phi^{\text {the }}} \geqslant 0 .
$$

We suppose the mechanical (often called intrinsic) and thermal effects uncoupled in (12):

$\phi^{\text {int }} \geqslant 0$ and $\phi^{\text {the }} \geqslant 0$.

Under the assumption of normal dissipation only depending on the internal variables (the material presents an instantaneous elasticity) and $T$, the behaviour law and the evolution equations of $\overline{\bar{C}}_{\mathrm{v}}$ and $T$ [11] are obtained:

$$
\left\{\begin{array}{l}
\overline{\bar{\pi}}=\rho_{0} \frac{\partial}{\partial \overline{\bar{F}}} \psi\left(\overline{\bar{C}}, \overline{\bar{C}}_{\mathrm{v}}, T\right), \\
\eta=\frac{\partial \psi}{\partial T}, \\
-\rho_{0} \frac{\partial}{\partial \overline{\bar{C}}_{\mathrm{v}}} \psi\left(\overline{\bar{C}}, \overline{\bar{C}}_{\mathrm{v}}, T\right)=\frac{\partial}{\partial \dot{\overline{\bar{C}}}_{\mathrm{v}}} \varphi^{\text {int }}\left(\dot{\overline{\bar{C}}}_{\mathrm{v}}\right), \\
-\frac{\operatorname{grad}_{X} T}{T}=\frac{\partial}{\partial \vec{q}} \varphi^{\text {the }}(\vec{q}) .
\end{array}\right.
$$

This yields for intrinsic dissipation:

$$
\phi^{\text {int }}=v \frac{\partial \varphi}{\partial \dot{\overline{\bar{C}}}_{\mathrm{v}}}: \dot{\overline{\bar{C}}}_{\mathrm{v}} \text {. }
$$

Remark 1. The high compressibility modulus of the considered elastomer and the range of the evolution of the temperature (see Section 5.4) make that the dilations induced by heating effect are very small and are thus negligible. Consequently, our model does not include thermal dissipation effect.

\subsection{Mechanical behaviour}

The mechanical constitutive equations are obtain by the generalization to large strain of the rheological model of Poynting-Thomson (Fig. 2). To argue from

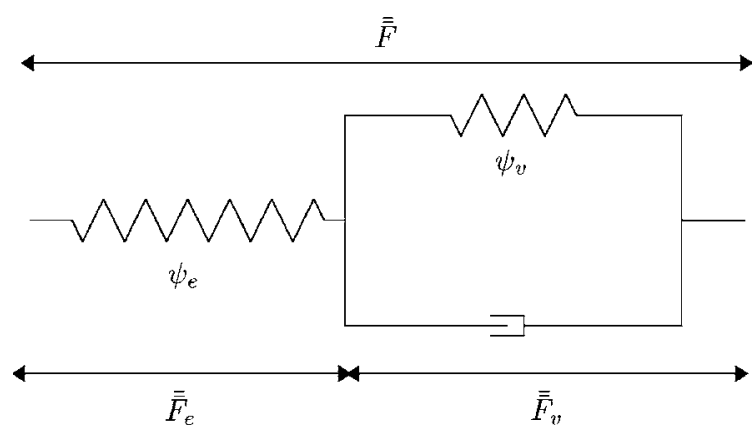

Fig. 2. Poynting-Thomson model. analogy with small perturbations, the total free energy is split into two parts $\psi_{\mathrm{e}}$ and $\psi_{\mathrm{v}}$. They are defined as the free specific energies associated respectively to elasticity and viscous responses of the material. For both these two quantities, we choose an incompressible hyperelastic law of Gent-Thomas for instantaneous elasticity $\left(\psi_{\mathrm{e}}\right)$ and a Neohooke one for $\psi_{v}$ :

$\left\{\begin{array}{l}\psi_{\mathrm{e}}=c_{1}(T)\left(I_{1}-3\right)+c_{2}(T) \ln \frac{I_{2}}{3}, \\ \psi_{\mathrm{v}}=a_{1}(T)\left(I_{1}-3\right) .\end{array}\right.$

The three material coefficients $c_{1}, c_{2}, a_{1}$ are experimentally determined and they are considered temperature dependent.

$\overline{\bar{C}}_{\mathrm{v}}$ The incompressibility constraint is applied to $\overline{\bar{C}}$ and

$\operatorname{det} \overline{\bar{C}}=1, \quad \operatorname{tr}\left(\overline{\bar{C}}_{\mathrm{v}} \cdot \overline{\bar{C}}_{\mathrm{v}}^{-1}\right)=0$.

The total free energy is then given by:

$\rho_{0} \psi(\overline{\bar{C}}, \overline{\bar{C}}, T)= \begin{cases}\rho_{0}\left(\psi_{\mathrm{e}}(\overline{\bar{C}}, T)+\psi_{\mathrm{v}}\left(\overline{\bar{C}}_{\mathrm{v}}, T\right)\right) & \text { if } \operatorname{det} \overline{\bar{C}}=1, \\ \infty & \text { otherwise. }\end{cases}$

The dissipation is assumed to only depend on the internal variable. The mechanical pseudo-potential of dissipation $\varphi$ is taken as a quadratic function of $\overline{\bar{C}}_{\mathrm{v}}$ :

$\varphi\left(\dot{\overline{\bar{C}}}_{\mathrm{v}}, T\right)= \begin{cases}\frac{1}{2} v(T) \dot{\overline{\bar{C}}}_{\mathrm{v}}: \dot{\overline{\bar{C}}}_{\mathrm{v}} & \text { if } \operatorname{tr}\left(\dot{\overline{\bar{C}}}_{\mathrm{v}} \cdot \overline{\bar{C}}_{\mathrm{v}}^{-1}\right)=0, \\ \infty & \text { otherwise }\end{cases}$

with $v$ a fourth material coefficient temperature dependent. The evolution of $v, c_{1}, c_{2}, a_{1}$ are determined at the same time (see Sections 4 and 5.1).

We then substitute (18) and (19) in (14) for the Poynting-Thomson rheological model:

$$
\left\{\begin{array}{l}
\pi=2 \rho_{0} \overline{\bar{F}}_{\mathrm{e}} \cdot\left[\left(\frac{\partial \psi_{\mathrm{e}}}{\partial I_{1}^{\mathrm{e}}}+\frac{\partial \psi_{\mathrm{e}}}{\partial I_{2}^{\mathrm{e}}} I_{1}^{\mathrm{e}}\right) \overline{\overline{1}}-\frac{\partial \psi_{\mathrm{e}}}{\partial I_{2}^{\mathrm{e}}} \overline{\bar{C}}_{\mathrm{e}}\right] \cdot \overline{\bar{F}}_{\mathrm{v}}^{-\mathrm{T}}+p \operatorname{cof} \overline{\bar{F}} \\
-\rho_{0} \overline{\bar{C}}_{\mathrm{v}}^{-1} \cdot \overline{\bar{C}} \cdot\left[\left(\frac{\partial \psi_{\mathrm{e}}}{\partial I_{1}^{\mathrm{e}}}+\frac{\partial \psi_{\mathrm{e}}}{\partial I_{2}^{\mathrm{e}}} I_{1}^{\mathrm{e}}\right) \overline{\overline{1}}-\frac{\partial \psi_{\mathrm{e}}}{\partial I_{2}^{\mathrm{e}}} \overline{\mathrm{C}}_{\mathrm{v}}^{-1} \cdot \overline{\bar{C}}\right] \cdot \overline{\bar{C}}_{\mathrm{v}}^{-1} \\
\quad+\rho_{0} \frac{\partial \psi_{\mathrm{v}}}{\partial I_{1}^{\mathrm{v}}}+v \dot{\overline{\bar{C}}}_{\mathrm{v}}+q \overline{\bar{C}}_{\mathrm{v}}^{-1}=0 \\
\operatorname{det} \overline{\bar{C}}=1, \\
\operatorname{tr}\left(\dot{\overline{\bar{C}}}_{\mathrm{v}} \cdot \overline{\bar{C}}_{\mathrm{v}}^{-1}\right)=0 .
\end{array}\right.
$$

where $p$ and $q$ are Lagrange multipliers which impose the incompressibility constraints $(20 \mathrm{c}$ and $\mathrm{d})$. Then 
multiplying (20b) by $\overline{\bar{C}}_{\mathrm{v}}$ and only considering its deviatoric part, $q$ is eliminated and we obtain:

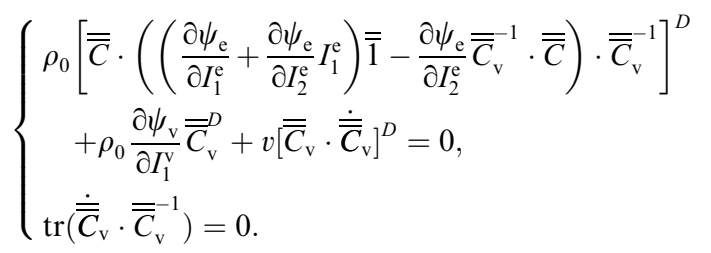

\subsection{Thermal behaviour}

The Piola-Kirschhoff heat flux $(\vec{Q})$ is given by the Fourier law written in the current configuration:

$\vec{Q}=-\overline{\bar{K}}_{L} \cdot \vec{\nabla}_{X} T(\vec{X}, T)$.

In this relation, the conductivity tensor $\left(\overline{\bar{K}}_{L}\right)$ is expressed in the initial configuration by:

$\overline{\bar{K}}_{L}=\overline{\bar{F}}^{-1} \cdot \overline{\bar{K}} \cdot \overline{\bar{F}}^{-\mathrm{T}}$,

$\overline{\bar{K}}$ being the usual Eulerian conductivity tensor.

\section{Coupling model}

\subsection{Constitutive equations}

\subsubsection{Mechanical problem}

The governing equations of the mechanical problem are given by the mass and momentum conservation laws, under the hypothesis of incompressibility medium:

$\frac{\rho}{\rho_{0}}=\operatorname{det} \overline{\bar{F}}=1 \quad \forall \vec{X} \in \Omega$,

$\rho_{0} \ddot{\vec{u}}=\operatorname{div} \overline{\bar{\pi}}+\rho_{0} \vec{f} \quad \forall \vec{X} \in \Omega$

with the boundary conditions (see Fig. 3(a)):

$$
\begin{cases}\overline{\bar{\pi}} \cdot \vec{N}=\vec{F} & \forall \vec{X} \in \partial \Omega_{F}, \\ \vec{u}=\vec{U}_{0} & \forall \vec{X} \in \partial \Omega_{U}, \\ \partial \Omega_{F} \cap \partial \Omega_{U}=\emptyset & \partial \Omega_{F} \cup \partial \Omega_{U}=\partial \Omega .\end{cases}
$$

It is pointed out that $\overline{\bar{\pi}}$ depends on the temperature through the coefficients $c_{1}, c_{2}, a_{1}$ and $v$ (see Section 2.3).

\subsubsection{Thermal problem}

The heat transfers are governed by the classical heat equation written in Lagrangian description [1]:

$\rho_{0} C_{\varepsilon} \dot{T}=-\operatorname{div} \vec{Q}+\rho_{0} r+D_{s}$,

where $C_{\varepsilon}$ is the heat capacity:

$C_{\varepsilon}=T \frac{\partial s}{\partial T}$,

$\rho_{0} r$ the classical internal source term and

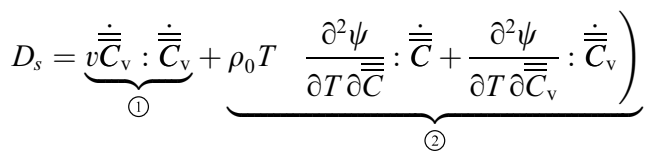

is the internal source term per volume unit in the initial configuration due to the mechanical problems. It can be split into two parts, (1) is the intrinsic mechanical dissipation and (2) represents the dependence between the thermal problem and mechanical one.

Remark 2. We will see later that the mechanical and the thermal problems will be solved sequentially. During one mechanical step $(<1 \mathrm{~s})$, the evolution of the temperature remains imperceptible. So we can consider that the term (2) can be neglected $\partial \psi / \partial T \rightarrow 0$. Thus the source term is reduced to the intrinsic dissipation.

The boundary conditions are given by (see Fig. 3(b))

$$
\begin{cases}\vec{Q}=\vec{Q}_{s} & \forall \vec{X} \in \partial \Omega_{Q}, \\ T=\theta & \forall \vec{X} \in \partial \Omega_{T}, \\ \partial \Omega_{Q} \cap \partial \Omega_{T}=\emptyset & \partial \Omega_{Q} \cup \partial \Omega_{T}=\partial \Omega .\end{cases}
$$

\subsection{Variational formulations}

For the mechanical problem the variational formulation of the quasi-static equilibrium problem is obtain

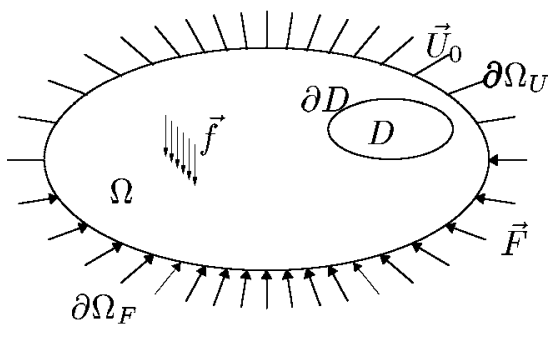

Mechanical Problem

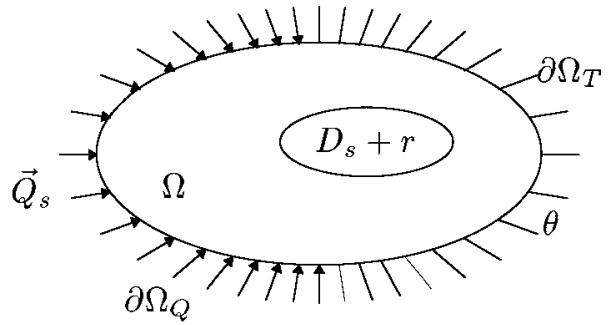

Thermal Problem

Fig. 3. Thermomechanical problem and boundary conditions. 
by a perturbed Lagrangian form. ${ }^{1}$ The solution $(\vec{u}, p)$ has to cancel the following integral form for all the test functions $\delta \vec{u}$ and $\delta p$ chosen respectively in the same spaces as those of the trial functions $\vec{u}$ and $p$ :

$$
\begin{aligned}
{\mathfrak{J}^{\mathrm{mec}}}^{(\vec{u}, p)=} & \int_{\Omega} \overline{\bar{\pi}}: \delta \overline{\bar{F}} \mathrm{~d} V-\int_{\partial \Omega_{F}} \vec{F} \cdot \delta \vec{u} \mathrm{~d} S \\
& -\int_{\Omega} \rho_{0} \vec{f} \cdot \delta \vec{u} \mathrm{~d} V+\int_{\Omega} \delta p(J-1-\alpha p) \mathrm{d} V,
\end{aligned}
$$

$\alpha$ is a perturbation term, which is equal to zero when the solution satisfies the incompressibility constraints (20c and d). If it is strictly positive but small, the obtained solution satisfies the quasi-incompressibility condition. For our problem, we take $\alpha=5 \times 10^{-4} \mathrm{MPa}^{-1}$.

The solution of the thermal problem has to cancel for all test functions $\delta T$ :

$$
\begin{aligned}
\mathcal{J}^{\text {the }}(T)= & -\int_{\partial \Omega_{Q}} \vec{Q} \cdot \vec{N} \delta T \mathrm{~d} S-\int_{\Omega}\left(D_{s}+\rho_{0} r\right) \delta T \mathrm{~d} V \\
& +\int_{\Omega}\left(\rho_{0} C_{p} \dot{T} \delta T+\vec{\nabla}_{L}(\delta T) \cdot \bar{K}_{L} \cdot \vec{\nabla}_{L}(T)\right) \mathrm{d} V .
\end{aligned}
$$

\subsection{Finite element approximation}

\subsubsection{Mechanical problem}

We choose for the mechanical problem a classical two-dimensional triangular finite element with a quadratic interpolation for the displacement and a constant pressure. It is commonly called $\mathrm{T} 6 / \mathrm{P} 1$. It verifies the discrete LBB condition and yields stable pressure approximations [30]. The hydrostatic pressure is assumed as an internal degree of freedom, which is eliminated by a static condensation at element level.

When we use an isoparametric interpolation the displacement is given by:

$\vec{u}=\left[N_{u}^{e}\right]\left\{U^{e}\right\}$,

$\{\overline{\bar{F}}\}=\left[B^{e}\right]\left\{U^{e}\right\}+\{\overline{\overline{1}}\}$,

and the constant pressure is given by:

$p=\left\langle N_{p}^{e}\right\rangle\left\{P^{e}\right\}$.

Eqs. (33)-(35) allow the discretization of (31). Then its resolution requires the implementation of an an iterative algorithm of Newton-Raphson giving, at each iteration, the linear system:

\footnotetext{
${ }^{1}$ This method is equivalent to a method of penalization with a reduced and selective integration technique $[2,24]$.
}

$$
\left\{\begin{array}{l}
\sum_{e=1}^{\text {Nelt }}\left\langle\delta U^{e}\right\rangle\left(\left[k_{t}^{e}\right]\left\{\Delta U^{e}\right\}+\left[g^{e}\right]\left\{\Delta P^{e}\right\}+\left\{r^{e}\right\}\right)=0, \\
\sum_{e=1}^{\text {Nelt }}\left\langle\delta g^{e}\right\rangle\left(\left[g^{e}\right]^{\mathrm{T}}\left\{\Delta U^{e}\right\}+\left[a^{e}\right]\left\{\Delta P^{e}\right\}+\left\{i^{e}\right\}\right)=0
\end{array}\right.
$$

with the elementary vectors and matrix given by:

- the tangent matrix:

$$
\left[k_{t}^{e}\right]=\int_{v^{e}}\left[B^{e}\right]^{\mathrm{T}}\left[\frac{\partial \overline{\bar{\pi}}}{\partial\left\{u^{e}\right\}}\right] \mathrm{d} v,
$$

- the residue vector:

$$
\begin{aligned}
\left\{r^{e}\right\}= & \int_{v^{e}}\left[B^{e}\right]^{\mathrm{T}}\{\overline{\bar{\pi}}\} \mathrm{d} v-\int_{v^{e}}\left[N_{u}^{e}\right]^{\mathrm{T}}\{\vec{f}\} \mathrm{d} v \\
& -\int_{v^{e} \cap \partial \Omega_{F}}\left[N_{u}^{e}\right]^{\mathrm{T}}\{\vec{F}\} \mathrm{d} s,
\end{aligned}
$$

- the incompressibility matrix:

$$
\left[g^{e}\right]=\int_{v^{e}}\left[B^{e}\right]^{\mathrm{T}}\{\operatorname{cof} \overline{\bar{F}}\}\left\langle N_{p}^{e}\right\rangle \mathrm{d} v,
$$

- the perturbation matrix:

$$
\left[a_{p}^{e}\right]=\alpha \int_{v^{e}}\left\{N_{p}^{e}\right\}\left\langle N_{p}^{e}\right\rangle \mathrm{d} v
$$

- and the incompressibility residue:

$$
\left\{i^{e}\right\}=\int_{v^{e}}\left\{N_{p}^{e}\right\}(J-1-\alpha p) \mathrm{d} v^{e} .
$$

After the static condensation, the iterative global system is finally obtained:

$\left[K_{t c}\right]\{\Delta u\}=\left\{R_{c}\right\}$

with

$\left\{\begin{array}{l}{\left[K_{t c}\right]=A_{e=1}^{\text {Nelt }}\left(\left[k_{t}^{e}\right]+\left[g^{e}\right]\left[a_{p}^{e}\right]\left[g^{e}\right]^{\mathrm{T}}\right),} \\ \left\{R_{c}\right\}=A_{e=1}^{\text {Nelt }}\left(-\left\{r^{e}\right\}+\left[g^{e}\right]\left[a_{p}^{e}\right]^{-1}\left\{i^{e}\right\}\right),\end{array}\right.$

where $A_{e=1}^{\text {Nelt }}$ represents the classical assembly operator of the finite elements method. ${ }^{2}$

\subsubsection{Thermal problem}

For the thermal problem, we use the same geometric discretization, but using a linear interpolation for temperature:

$T=\left\langle N_{\theta}^{e}\right\rangle\left\{T^{e}\right\}$.

Using (44), the integral form (32) leads to:

$\left[M_{\theta}\right]\{\dot{T}\}+\left[K_{\theta}\right]\{T\}=\left\{F_{\theta}\right\}$

\footnotetext{
${ }^{2}$ This operator allows to pass from vectors or matrix $\left(\left[k_{t}^{e}\right]\right.$, $\left.\left\{r^{e}\right\} \cdots\right)$ to the global matrix $\left[K_{t c}\right]$ and to the global vector $\left\{R_{c}\right\}$.
} 
with the mass matrix, the stiffness matrix and the body forces given by:

$$
\begin{aligned}
& {\left[M_{\theta}\right]=\stackrel{\text { Nelt }}{A}\left[\int_{e=1} \rho_{v^{e}} C_{p}\left\{N_{\theta}^{e}\right\}\left\langle N_{\theta}^{e}\right\rangle \mathrm{d} v\right]} \\
& {\left[K_{\theta}\right]=\stackrel{\text { Nelt }}{A}\left[\int_{v^{e}}\left[B^{e}\right]^{\mathrm{T}}\left[K_{L}\right]\left[B^{e}\right] \mathrm{d} v\right]} \\
& \left\{F_{\theta}\right\}=\underset{e=1}{A}\left[\int_{v^{e}}\left\{N_{\theta}^{e}\right\}\left(D_{s} \cdot+\rho_{0} r\right) \mathrm{d} v^{e}+\int_{v^{e} \cap \partial \Omega_{Q}}\left\{N_{\theta}^{e}\right\} \vec{Q} \cdot \vec{N} \mathrm{~d} s\right] .
\end{aligned}
$$

Then the differential system (45) is solved by an implicit Eulerian time integration scheme.

\subsection{Local solving of complementary law}

The construction of the mechanical elementary matrices and vectors requires the evaluation, at each integration point, of the internal variable $\overline{\bar{C}}_{\mathrm{v}}$ and the derivative term $\partial \overline{\bar{C}}_{\mathrm{v}} / \partial \overline{\bar{F}}$. The complementary law (21) is summarized by:

$$
\left\{\begin{array}{l}
\dot{\overline{\bar{C}}}_{\mathrm{v}}=\overline{\bar{\chi}}\left(t, \overline{\bar{F}}(t), \overline{\bar{C}}_{\mathrm{v}}(t)\right) \quad \text { on }\left[t_{0}, t_{0}+\Delta t\right], \\
\overline{\bar{C}}_{\mathrm{v}}\left(t_{0}\right)=\overline{\bar{C}}_{\mathrm{v}}^{0}
\end{array}\right.
$$

By means of an implicit Eulerian scheme, (49) gives on $\left[t_{n}, t_{n}+\delta t\right]$ a sub-interval of $\left[t_{0}, t_{0}+\Delta t\right]$ :

$\overline{\bar{C}}_{\mathrm{v}}\left(t_{n+1}\right)=\overline{\bar{C}}_{\mathrm{v}}\left(t_{n}\right)+\delta t \overline{\bar{\chi}}\left(t_{n+1}, \overline{\bar{F}}\left(t_{n+1}\right), \overline{\bar{C}}_{\mathrm{v}}\left(t_{n+1}\right)\right)$

which is solved by a Newton-Raphson scheme.

The term $\partial \overline{\bar{C}}_{\mathrm{v}} / \partial \overline{\bar{F}}$ is given by the linear system:

$$
\left\{\begin{array}{l}
\frac{\mathrm{d} \overline{\overline{\bar{C}}}_{\mathrm{v}}}{\mathrm{d} \overline{\bar{F}}}=\frac{\partial \overline{\bar{\chi}}}{\partial \overline{\bar{C}}_{\mathrm{v}}}: \frac{\partial \overline{\bar{C}}_{\mathrm{v}}}{\partial \overline{\bar{F}}}+\frac{\partial \overline{\bar{\chi}}}{\partial \overline{\bar{F}}} \quad \text { on }\left[t_{0}, t_{0}+\Delta t\right], \\
\left.\frac{\partial \overline{\bar{C}}_{\mathrm{v}}}{\overline{\bar{F}}}\right|_{t=t_{0}}=0 .
\end{array}\right.
$$

Using the approximate solution of (51) (and thus the same time step) (51) can be solved by a Crank-Nicholson scheme.

\subsection{Coupling algorithm}

The time scale of the mechanical problem is assumed to be smaller than the thermal one in this algorithm. Thus these problems can be solved separately. Considering an evolution of the mechanical parameters experimentally determined, the algorithm described Fig. 4 is adopted.

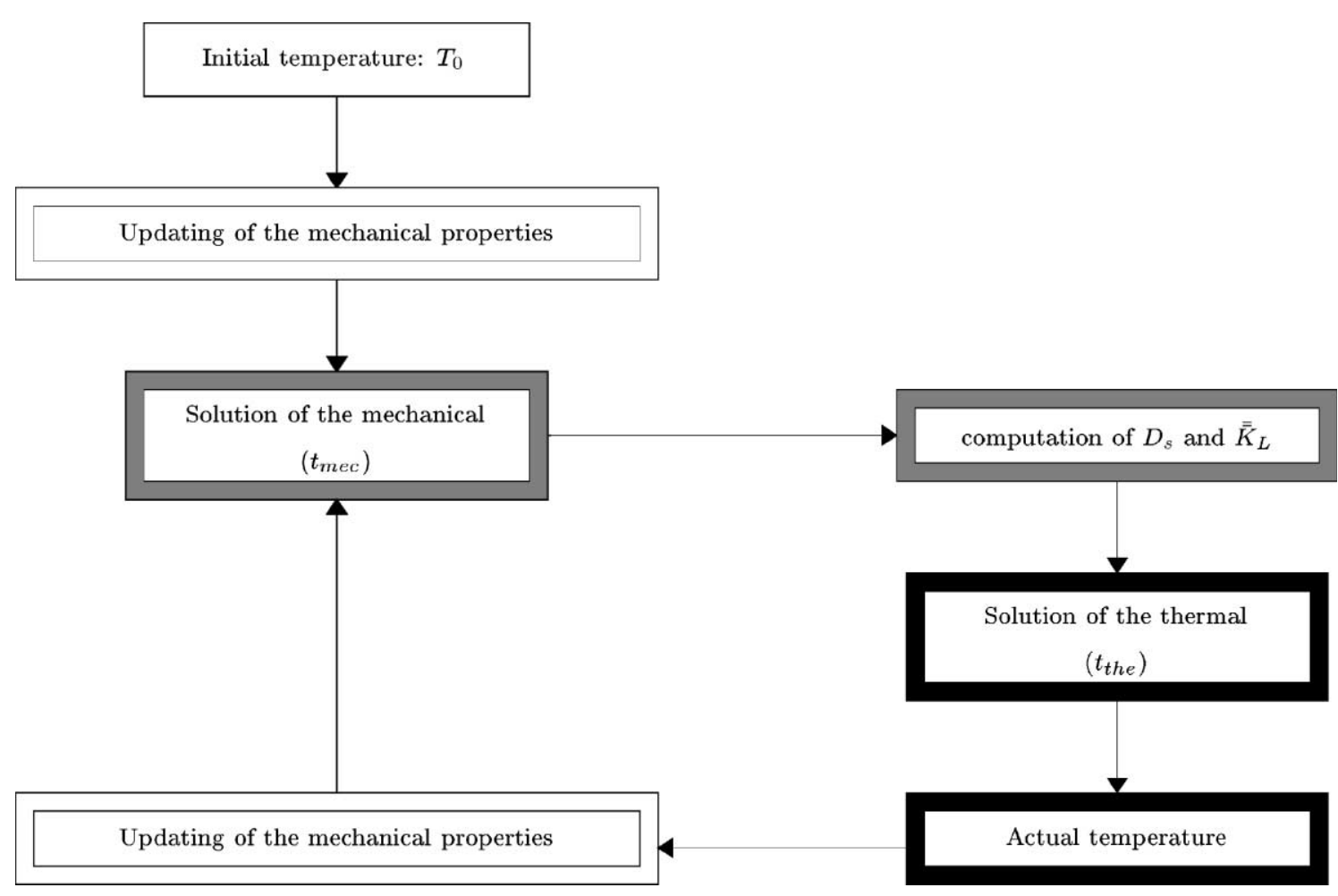

Fig. 4. Coupling algorithm. 
We first start from a mechanical computation, after stabilization, a mechanical term source (the mechanical dissipation or its average, see Section 5.2) and eventually the gradient transformation are transmitted to the thermal model. We can now run a thermal simulation, once the evolution of the temperature is sufficient, the mechanical properties are updated, a new mechanical computation is started, and so on.

An appropriate choice of $t_{\text {mec }}$ and $t_{\text {the }}$ (Fig. 4) could lead to the same time scales for the mechanical an thermal computations.

\section{Identification of the mechanical characteristics}

The identification procedure consists in a least square fitting. Cyclic loadings (broken line, Fig. 5(b)) are used. These experimental data are decomposed in two: the average stress of a stabilized cycle (broken line, Fig. 5(a)) and the stress difference at constant strain during the rise and fall of the hysteresis curve (broken line, Fig. $5(\mathrm{c}))$.

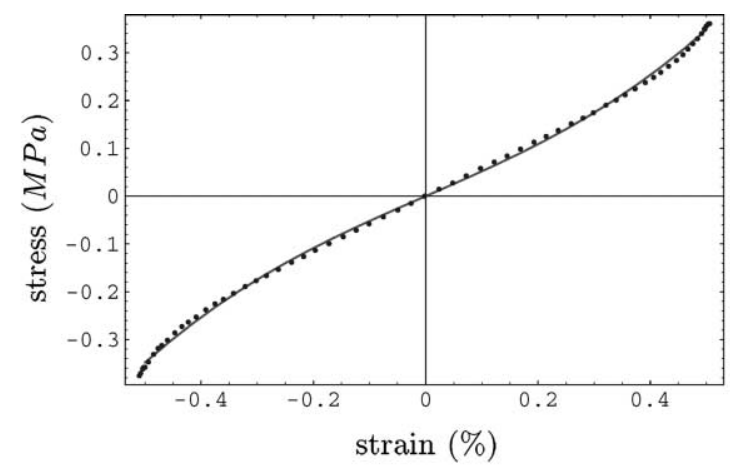

(a) Experimental average stress and numerical identification of Gent-Thomas model.

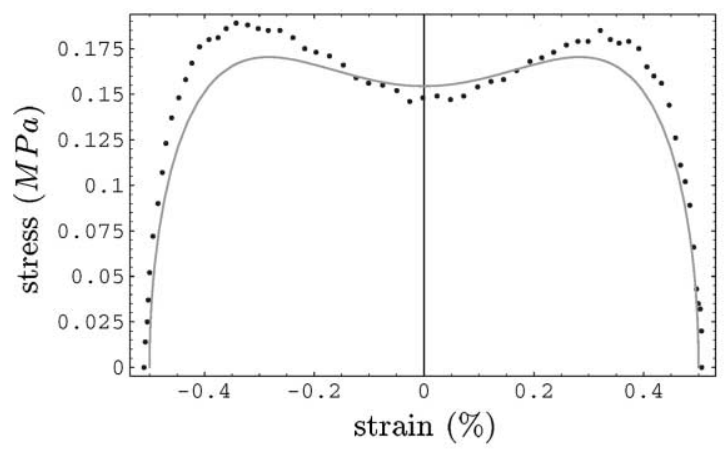

(c) Experimental and numerical stress difference.
Identifying the average curve to a shearing hyperelastic curve (Gent-Thomas model) (continuous line, Fig. 5(a)), a first value $\left(C_{1}, C_{2}\right)$ is determined. Then from this result, a correction and a complete determination is provided according to an heuristic method (continuous line, Fig. 5(b)-(d)) and a set of variables $\left(C_{1}, C_{2}, A_{1}, v\right)$ is finally obtained.

\section{Numerical simulation}

The different tests are realized on a two-layer elastomer-steel test piece (Fig. 6(a)). The elastomer part is made dimethyl-vinyl-siloxan vulcanized by peroxide.

This test piece is put into a thermal enclosure at a constant temperature and subjected to a cyclic shearing deformation, $\gamma(t)=\Gamma \sin (2 \pi f t)$, with a frequency $f$ of 3.1 Hz. The amplitude $\Gamma$ defines the relative shearing displacement applied to the external armatures while the central armature is clamped.

Two thermocouples measure the temperature on one of the elastomeric layers (Fig. 6(a)).

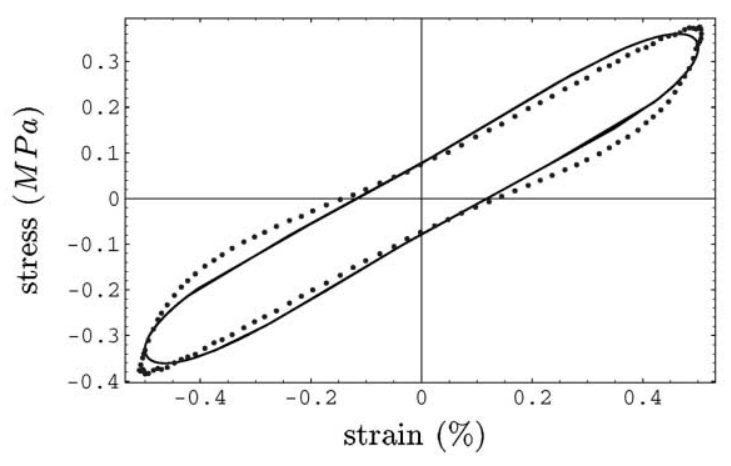

(b) Experimental and numerical hysteresis.

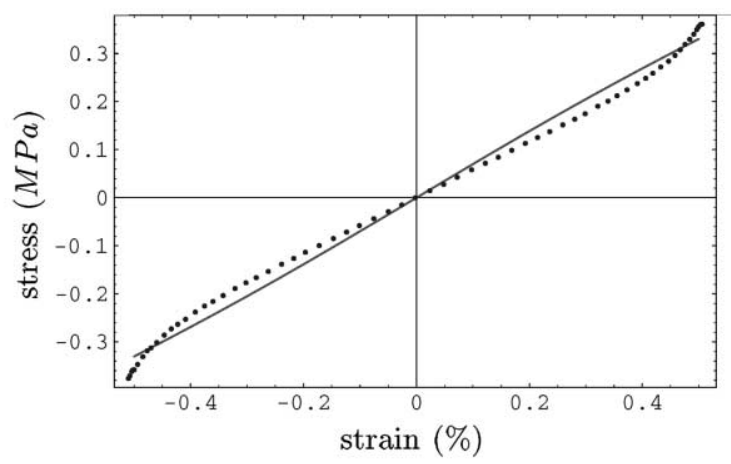

(d) Experimental and numerical average stress.

Fig. 5. Experimental $(\cdots)$ and identified (-) curves. 


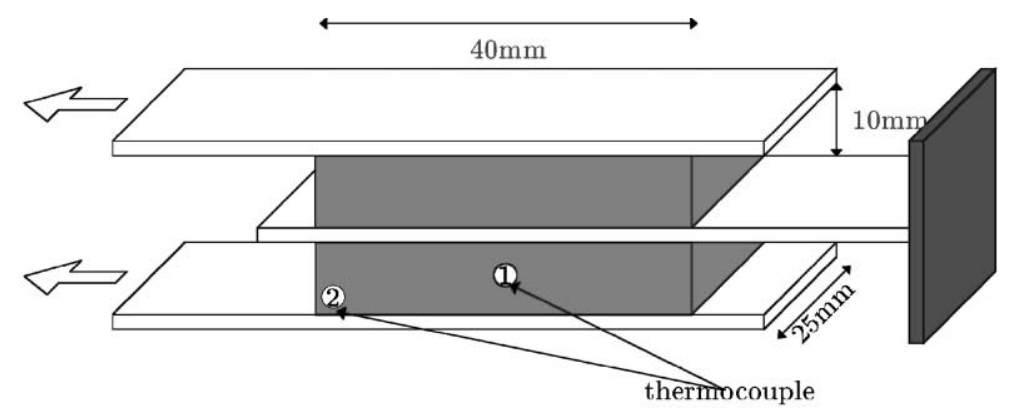

(a) Two-layer test piece.

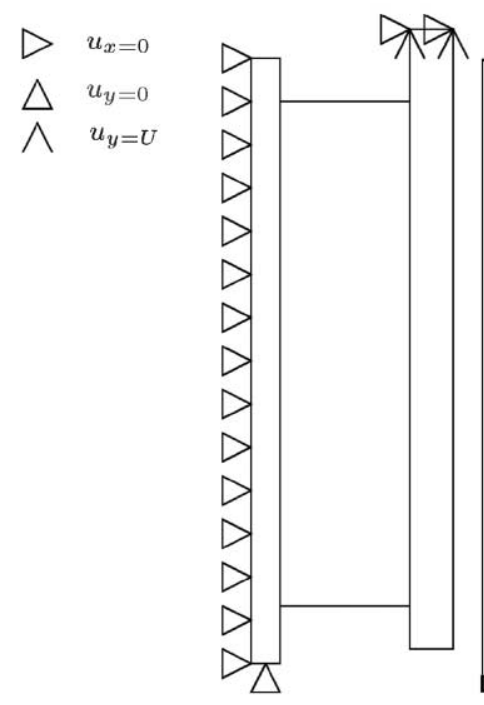

(b) Mechanical boundary conditions.

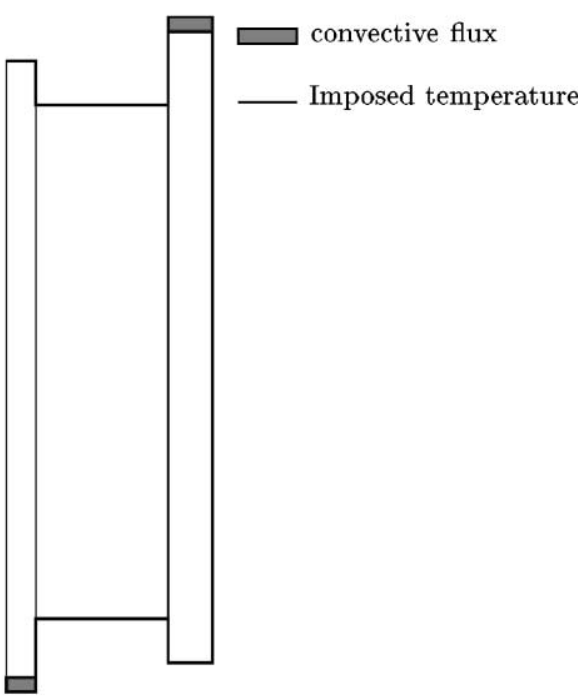

(c) Thermal boundary conditions.

Fig. 6. Physical and numerical problems.

\subsection{Modelisation}

Due to the symmetry of the problem, the computation of this shearing test has been carried out on a half cross-section of the test piece.

For the thermal problem (Fig. 6(c)), linear triangular, linear quadrilateral and linear flux elements are used to mesh respectively the elastomeric layer, the metallic armatures and the boundaries. A zero flux condition is applied on the symmetry axis and a convective heat transfer condition is imposed on other boundaries:

$\vec{Q}=-h\left(T-T_{0}\right) \vec{N}$,

where $h$ is convective heat coefficient and $T_{0}$ the temperature of the thermal enclosure. The values of the thermal properties of the materials are declined Table 1.

For the mechanical problem (Fig. 6(b)), using the plane strains hypothesis, the mesh is the same as the
Table 1

Thermal properties

\begin{tabular}{lll}
\hline & Elastomer & Steel \\
\hline$K\left(\mathrm{~W} \mathrm{~m}^{-1} \mathrm{~K}^{-1}\right)$ & 0.127 & 45 \\
$\rho_{0} C_{\varepsilon}\left(\mathrm{J} \mathrm{m}^{-3} \mathrm{~K}^{-1}\right)$ & $0.74 \times 10^{6}$ & $3.5 \times 10^{6}$ \\
$h\left(\mathrm{~W} \mathrm{~m}^{-2} \mathrm{~K}^{-1}\right)$ & 17 & 30 \\
\hline
\end{tabular}

thermal one (without the linear flux elements), but a quadratic interpolation is used. The boundary conditions are:

- no displacement on the fixed edge of the central armature,

- a sinusoidal displacement on the loaded edges of outer armatures.

Moreover, on the symmetry axis, the normal displacement is fixed to zero. The mechanical properties of 
Table 2

Mechanical properties of steel

\begin{tabular}{ll}
\hline Young modulus $E(\mathrm{MPa})$ & 210000 \\
\hline Poisson ratio $v$ & 0.3 \\
\hline
\end{tabular}

the materials are given Table 2. For the elastomer, as we said, the parameters of the mechanical model are assumed to be temperature dependent. They are determined from experimental measurements. These tests were realized for different temperature and followed by an interpolation law in order to obtain the evolution according to the temperature (Fig. 7).

\subsection{Algorithm influence}

The problem have to be solved on $14 \mathrm{~s}$, so we consider two different configurations of the presented algorithm (see Fig. 4):

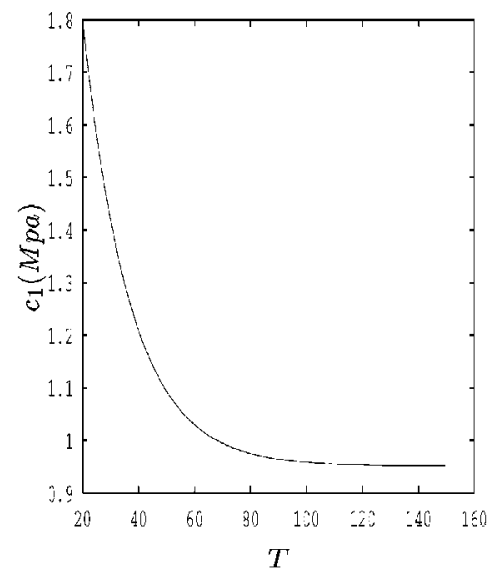

(a) $c 1(T)$

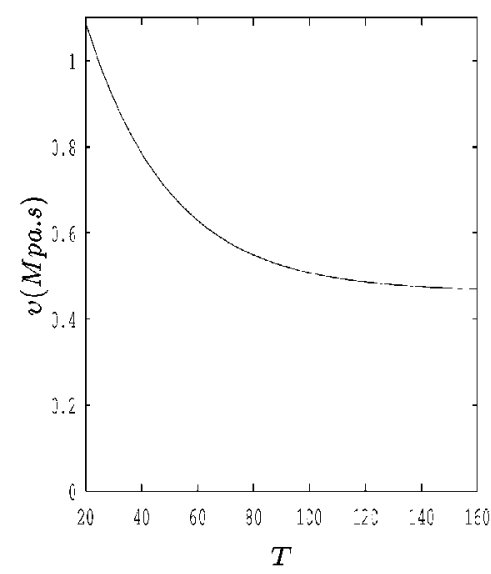

(c) $v(T)$
- First configuration: the natural configuration

- $D_{s}=\phi_{0}$ : mechanical source term,

- $T_{\mathrm{mec}}=T_{\text {the }}=0.02 \mathrm{~s}$,

- the thermal computation is realized considering the deformed geometry (i.e. computation of $\bar{K}_{L}$ ).

- Second configuration: the "simplified" configuration According with Holzapfel and Simo [15] and Lion [22], the periodicity of the mechanical loading gives to the dissipation the same propriety (this phenomena is numerically verified on our model). So we choose a simplified configuration:

- $D_{s}=\bar{\phi}_{0}(t)=\frac{\int_{0}^{t} \phi_{0}(s) \mathrm{d} s}{t}$,

- $T_{\text {mec }}=0.93$ s (i.e. after three mechanical cycles, the dissipation is considered stabilized),

$-T_{\text {the }}=14 \mathrm{~s}$,

- the thermal computation is realized on undeformed geometry.

The spatial discretization is given Fig. 9(b) and its characteristics Table 3. We verify on Fig. 8 that the two

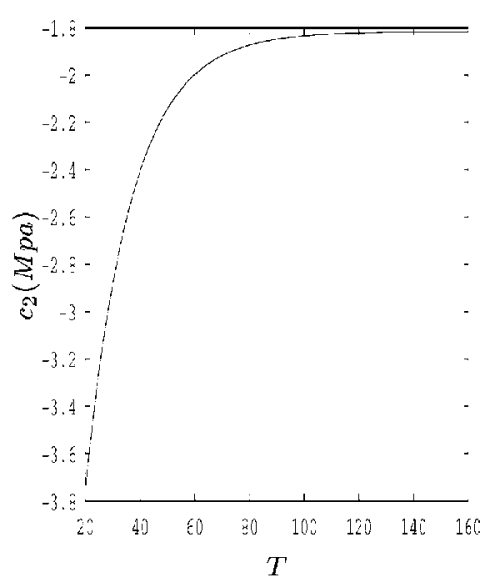

(b) $c 2(T)$

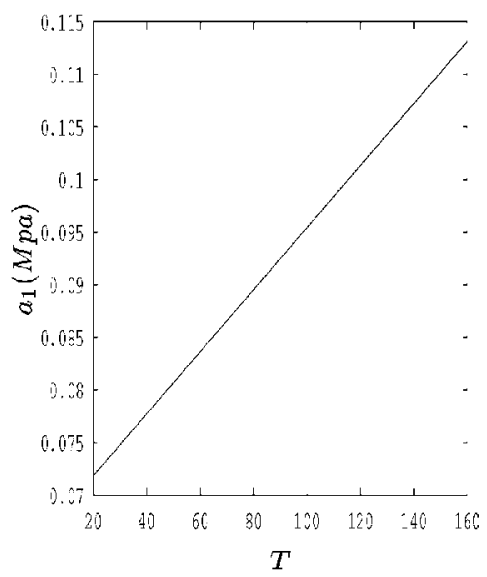

(d) $a 1(T)$

Fig. 7. Elastomer parameters according to the temperature. 
Table 3

Numbers of elements and degrees of freedom according to the problem and the refinement

\begin{tabular}{lccccccc}
\hline & \multicolumn{2}{l}{ Mechanical problem } & & \multicolumn{2}{c}{ Thermal problem } \\
\cline { 2 - 4 } & Elements & d.o.f. (displacement) & d.o.f. (pressure) & & Elements & d.o.f. (temperature) \\
\hline Refinement (a) & 130 & 742 & 80 & 320 & 171 & 121 \\
Refinements (b) and (d) & 400 & 1938 & 6250 & 1280 & 459 & 285 \\
Rrefinement (c) & 1420 & 6250 & 1515 & 853 \\
\hline
\end{tabular}

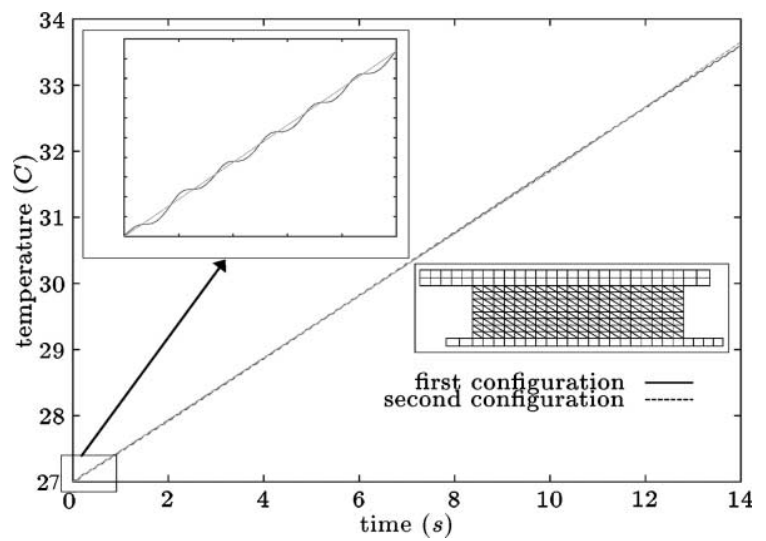

Fig. 8. Temperature evolution in the middle of the elastomeric layer. Comparison between the two configurations.

configurations algorithm give quite the same results. On the zoom, it is possible to see that the evolution obtained by the first repartition oscillate around the temperature obtained by the second one. More precisely, these oscillations have a period of two mechanical periods, be- cause the dissipation is maximum when the mechanical loading is maximal or minimal. The first configuration need a CPU time fourteen time more important that the second one. For this reason, a generalization of the second configuration is adopted for the rest of the study, the $i$ th cycle of it being:

$$
\left[\begin{array}{l}
\text { mechanical computation }\left(\Delta t_{\mathrm{mec}}=0.888 \mathrm{~s}\right) \\
+ \text { thermal computation }\left(\Delta t_{\text {the }}^{i}=2^{i-1} \times 10 \mathrm{~s}\right) .
\end{array}\right.
$$

\subsection{Space discretization influence}

\subsubsection{Mesh refinement}

Three spatial discretizations are declined (Fig. 9) and their characteristics are given in Table 3. In Fig. 10(a), we examine the maximum of the power balance obtained during the first mechanical computation, i.e. the quantity:

$\rho_{0} \dot{\psi}-\overline{\bar{\pi}}: \dot{\bar{F}}-\phi^{\text {int }}$.

Fig. 10(b) shows the maximum of the reactions reached during the the same mechanical time. At last, on Fig. $10(\mathrm{c})$, temperatures in the center (thermocouple 1,

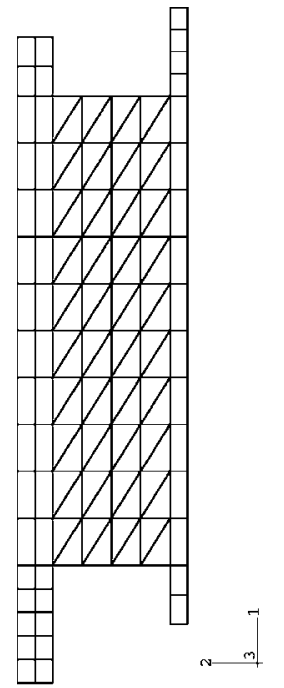

(a) Mesh a.

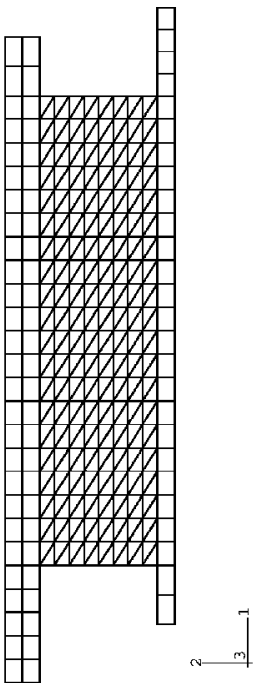

(b) Mesh b.

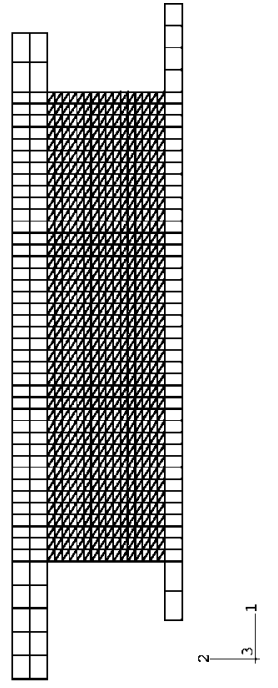

(c) Mesh c.

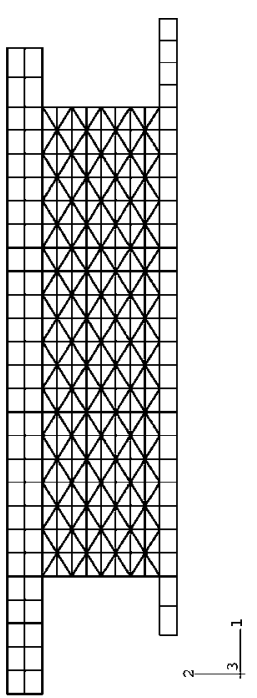

(d) Mesh d.

Fig. 9. Mesh refinement. 


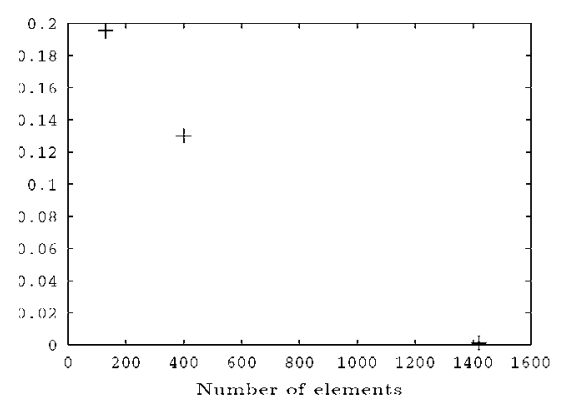

(a) Power balance $\left(M W m^{-3}\right)$.

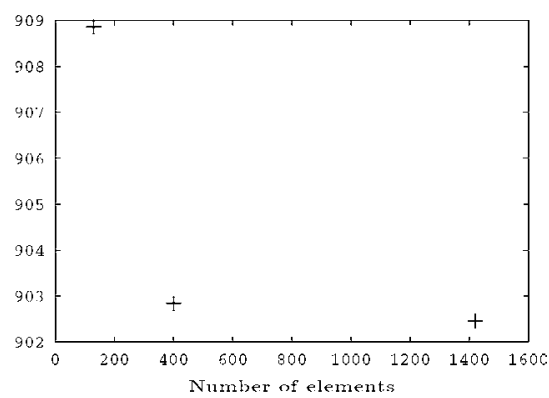

(b) Reaction $(N)$.

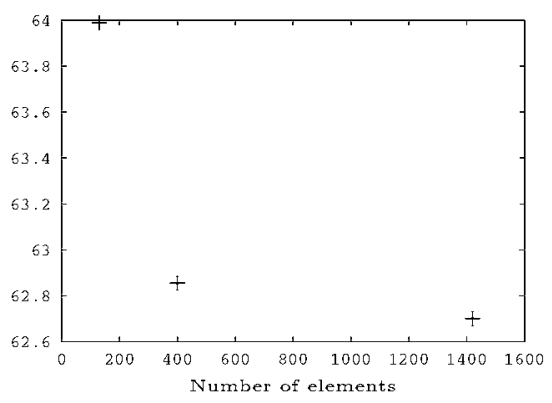

(c) Temperature $\left({ }^{\circ} \mathrm{C}\right)$

Fig. 10. Mesh refinement influence.

Fig. 6(a)) of the elastomeric layer are compared at the time $40 \mathrm{~s}$ for the three meshes.

All these investigations point that the more accurate mesh (c) gives the best results; but it also provides the more important CPU times. A good compromise between results validity and computational time, if the power balance is excluded, seems to be the mesh (b).

\subsubsection{Type of mechanical spatial discretization}

In this paragraph, the meshes (b) and (d) (Fig. 9(b) and (d)) are compared for a mechanical computation. These two discretizations present the same number d.o.f. (in displacement and pressure) and the same number of elements. We can see Fig. 11 that the mesh (d) is less conservative than the mesh (b).

\subsection{Comparison with experiment}

All the previous tests give a good idea of the space and times discretization to adopt.

From these results, two tests are realized, considering respectively a temperature of 25 and $60{ }^{\circ} \mathrm{C}$ for the thermal enclosure. The numerical results are compared on two positions (1), (2) see Fig. 12) with the experimental ones. This comparison gives a good agreement, and seems to validate the adopted discretizations (space and time) and at last the thermomechanical model.

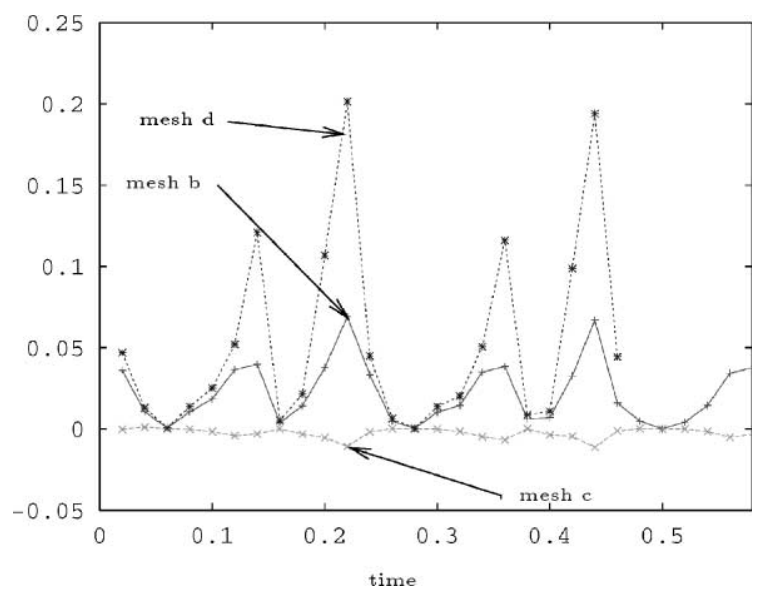

Fig. 11. Power balance over time $\left(\mathrm{MW} \mathrm{m}^{-3}\right)$ - first mechanical cycle.

\section{Conclusion}

A new model has been developed to deal with mechanical and thermal problems, allowing for the interaction of both these phenomena. This explicit coupling has a solving algorithm adaptable to the two distinct time-scales. For the mechanical model, an hyperviscoelastic behavior is proposed. The thermal formulation is 


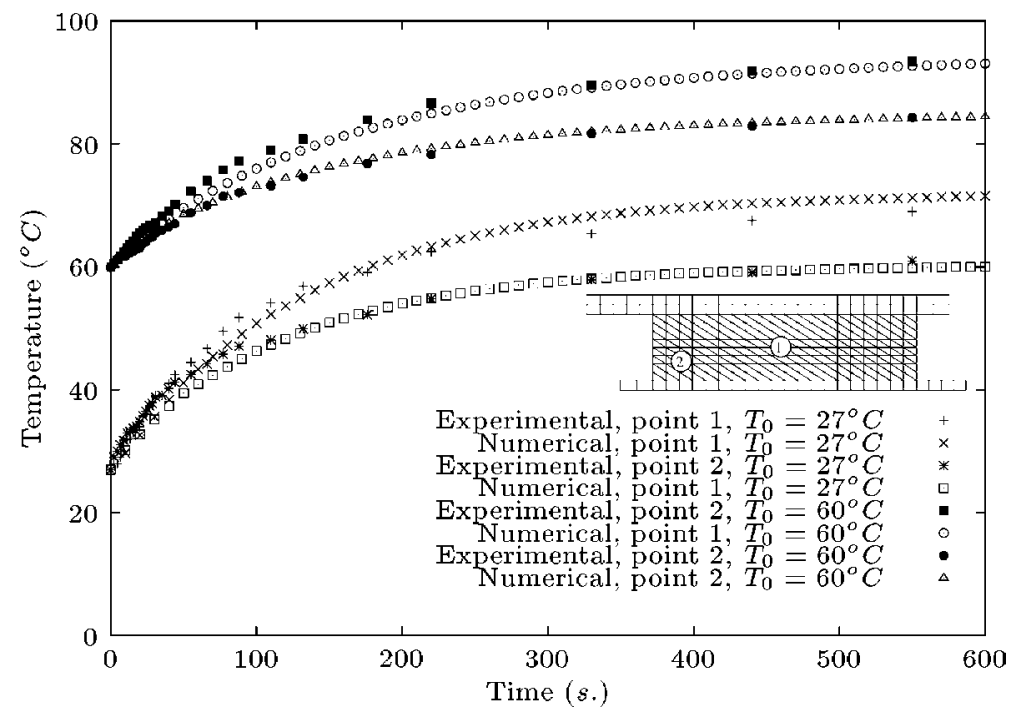

Fig. 12. Evolution of the temperature on two points of an elastomeric layer. Experimental and numerical results.

carried out under finite transformation hypothesis in the Lagrangian configuration in order to fit it to the mechanical formulation.

A study of space discretization allows to determine an appropriate refinement of mesh and a good pattern for it. We also obtain the increase of stiffness experimentally observed.

Finally, on a sinusoidal mechanical loading at two different initial temperatures, a comparison between numerical and experimental results gives some good results.

\section{References}

[1] Bérardi G. Modélisation numérique du comportement thermo-viscoélastique dun élastomère en grandes déformations, 1995.

[2] Carey GF, Oden JT. Finite elements. NJ: Prentice-Hall; 1986. vol. 2.

[3] Chang WV, Bloch R, Tschoegl NW. The behaviour of rubber-like materials in moderately large deformations. J Rheol 1978;22:1-32.

[4] Christensen RM. Theory of viscoelasticity, an introduction. New York: Academic Press Inc; 1971.

[5] Coleman BD. Thermodynamics of materials with memory. Arch Rational Mech Anal 1964;17:1-46.

[6] Coleman BD, Noll W. Foundations of linear viscoelasticity. Rev Mod Phys 1961;33:239-49.

[7] Germain P, Mécanique 1 et 2. Cours de 1Ecole Polytechnique. Ellipses, 1986.

[8] Glowinski R, Le Tallec P. Numerical solution of problems in incompressible finite elasticity by augmented Lagrangian methods, 2. Three-dimensional problems. SIAM J Appl Math 1984;44:710-33.

[9] Govindjee S, Simo J. Trasnsition from micro-mechanics to computationally efficient phenomenology: carbon black filled rubbers incorporating Mullins effect. J Mech Phys Solids 1992;40:213-33.

[10] Govindjee S, Simo JC. A micro-mechanically based continuum damage model for carbon black-filled rubbers incorporating Mullins effect. J Mech Phys Solids 1991; 39:87-112.

[11] Halphen B, Son NQ. Sur les matériaux standards généralisés. J Méch 1975;14:39-63.

[12] Hart-Smith LJ. Elasticity parameters for finite deformations of rubber-like materials. J Appl Math Phys 1966;17: 608-26.

[13] Harwood JAC, Mullins L, Payne AR. Stress softening in rubbers: a review. J IRI 1967:17-27.

[15] Holzapfel GA, Simo J. Entropy elasticity of isotropic rubber-like solids at finite strains. Comput Meth Appl Mech Eng 1996;132:17-44.

[16] Holzapfel GA, Simo J. A new viscoelastic constitute model for continuous media at finite thermomechanical changes. Int J Struct 1996;33:3019-34.

[17] Le Tallec P. Numerical analysis of viscoelastic problems. Paris: Masson; 1990.

[18] Le Tallec P, Rahier C. Numerical models of steady rolling for non-linear viscoelastic structures in finite deformations. Int J Numer Meth Eng 1994;37:1159-86.

[19] Lemaître J, Chaboche JL. Mécanique des matériaux solides. Paris: Dunod; 1996.

[20] Leonov AI. On thermodynamics and stability of general Maxwell-like viscoelastic constitutive equations, theoretical and applied rheology. In: XIth International Congress on Rheology. 1992. p. 97-9.

[21] Lianis G. Constitutive equations of viscoelastic solids under finite deformation. Purdue University Report, A\&ES 6311, 1963.

[22] Lion A. On the large deformation behaviour of reinforced rubber at different temperatures. J Mech Phys Solids 1997;45:1805-34.

[23] Malkus DS. Finite element with penalties in nonlinear elasticity. Int J Numer Meth Eng 1980;16:121-36. 
[24] Malkus DS, Hughes TJR. Mixed finite element methodsreduced and selective integration techniques: a unification of concepts. Comput Meth Appl Mech Eng 1978;15: $63-81$.

[25] Miehe C. Discontinuous and continuous damage evolution in Ogden-type large-strain elastic materials. Eur J Mech, A/Solids 1995; 14:697-720.

[26] Mooney M. A theory of large elastic deformation. J Appl Phys 1940;11:582-92.

[27] Morman KN. Original contributions. an adaptation of finite linear viscoelasticity theory for rubber-like by use of the generalised strain measure. Rheol Acta 1988;27:3-14.

[28] Mullins L. Effect of strectching on the properties of rubber. J Rubber Res 1947;16:275-89.

[29] Oden JT. A theory of penalty methods for finite element approximations of highly nonlinear problems in continuum mechanics. Comput Struct 1978;8:445-9.

[30] Oden JT, Kikuchi N. Finite element methods for constrained problems in elasticity. Int $\mathrm{J}$ Numer Meth Eng 1982;18:701-25.

[31] Ogden RW. Large deformation isotropic elasticity, on the correlation of theory and experiment for incompress- ible rubber-like solids. Proc Roy Soc, Lond A 1972;326: 565-84.

[32] Rivlin RS. Some topics in finite elasticity. In: 1st Symp on Naval Struct Mech, Stanford, August 11-14, 1958.

[33] Sidoroff F. The geometrical concept of intermediate configuration and elastic finite strain. Arch Mech 1973;25(2): 299-309.

[34] Sidoroff F. Un modèle viscoélastique nonlinéaire avec configuration intermédiaire. J Méch 1974;13(4):679-713.

[35] Sidoroff F. Variables internes en viscoélasticité, 1. Variable internes scalaires et tensorielles. J Méch 1975;14(3):545-66.

[36] Sidoroff F. Rhéologie non-linéaire et variables internes tensorielles. In: Symposium Franco-Polonais, Cracovie, 1977.

[37] Simo JC. On a fully three-dimensional finite-strain viscoelastic damage model: formulation and computational aspects. Comp Meth Appl Mech Eng 1987;60:153-63.

[38] Treloar LRG. The elasticity of a network of long chain molecules $i$. Trans Faraday Soc 1943;39:36-64.

[39] Treloar LRG. The present status of the theory of large elastic deformations. In: The Rheology of Elastomers, 1957. 